\title{
INFLUENCE OF INTRACRANIAL HEM ORRHAGE AND NEONATAL SEIZURES ON THE NEUROLOGICAL AND PSYCHOMOTOR DEVELOPMENT OF PREM ATURE INFANTS AT HOSPITAL DE CLÍNICAS DE PORTO ALEGRE, BRAZIL
}

\author{
Lygia Ohlweiler ${ }^{1}$, Alexandre Rodrigues da Silva², \\ Sonja Vergínia Barros², Rudimar Riesgo ${ }^{1}$, Newra Tellechea Rotta ${ }^{3}$
}

\begin{abstract}
This study compared the results of neurodevelopmental examination at 6 months' corrected age of premature infants with neonatal seizures and/or intracranial hemorrhage and normal premature infants. There was a statistically significant correlation $(p=0.000007)$ between intracranial hemorrhage and seizures in the group of 68 premature infants seen in the neurodevelopmental outpatient service at Hospital de Clínicas de Porto Alegre, Brazil. Intracranial hemorrhage was significantly associated with multiparity $(p=0.02)$. The neurodevelopmental examination at 6 months' corrected age revealed that patients who suffered neonatal intracranial hemorrhage and/or seizures had inappropriate muscle tone, strength and reflexes, as well as delay in head control. Conclusion: we compared the results of neurodevelopmental examinations of two groups of premature infants at 6 months' corrected age. The difference in neurological development at 6 months' corrected age was statistically significant when comparison was corrected for premature infants who had neonatal seizures and periventricular hemorrhage.
\end{abstract}

KEY WORDS: neurological and psychomotor development, neonates, intracranial hemorrhage, neonatal seizures.

\begin{abstract}
Influência da hemorragia intracraniana e crises neonatais sobre o desenvolvimento neurológico e psicomotor de recém-nascidos prematuros no Hospital de Clínicas de Porto Alegre, Brasil
\end{abstract}

\begin{abstract}
RESUMO - Este estudo comparou os resultados do exame do desenvolvimento neuropsicomotor aos seis meses de idade corrigida de lactentes prematuros com crises neonatais e/ou hemorragia intracraniana com lactentes prematuros sem estas intercorrências. Houve uma correlação estatisticamente significativa $(p=0.000007)$ entre hemorragia intracraniana e crises neonatais no grupo de 68 lactentes prematuros vistos no ambulatório de neurodesenvolvimento do Hospital de Clínicas de Porto Alegre, Brasil. Hemorragia intracraniana foi significativamente associada com multiparidade $(p=0.02)$. 0 exame do desenvolvimento neuropsicomotor aos 6 meses de idade corrigida mostrou que pacientes que sofreram hemorragia intracraniana neonatal e/ou crises neonatais tiveram tônus, forças e reflexos inapropriados, bem como atraso no controle do sustento cefálico. Conclusões: Comparamos os resultados dos exames de desenvolvimento neuropsicomotor dos dois grupos de lactentes prematuros aos 6 meses de idade corrigida. A diferença no desenvolvimento neurológico aos 6 meses de idade corrigida foi estatisticamente significativa quando comparado com lactentes prematuros que tiveram crises neonatais e/ou hemorragia periventricular.
\end{abstract}

PALAVRAS-CHAVE: desenvolvimento neurológico e psicomotor, recém-nascidos, hemorragia intracraniana, crises neonatais.

Prematurity is a biological event with very distinct and sometimes exclusive characteristics ${ }^{1}$. This event, which may or may not affect the future life of premature infants, has been investigated for a long time ${ }^{2,3}$. Premature infants are neurologically different from term infants because they do not complete certain intrauterine neurodevelopmental stages ${ }^{3,4}$. Few parameters have been established to assess the neurological and psychomotor development (NPMD) of premature infants. Data about the NPMD of prema-

Unidade de Neurologia Pediátrica do Hospital de Clínicas de Porto Alegre (HCPA), Serviço de Pediatria do HCPA, Faculdade de Medicina

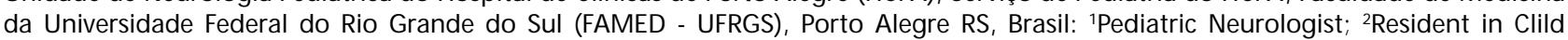
Neurology; ${ }^{3}$ Head of the Pediatric Neurology Unit.

Received 14 June 2002, received in final form 29 May 2003. Accepted 30 June 2003.

Dra. Lygia Ohlweiler - Avenida Pirapó 71/702 - 90470-450 Porto Alegre RS - Brasil. E-mail: fp54@terra.com.br 
ture infants who had neonatal seizures or intracranial hemorrhage are even harder to obtain. Moreover, comparing the neurological status of premature infants with that of term infants would be a serious error ${ }^{5,6}$. The neurodevelopmental examination is a useful tool in the assessment of these patients, who may have a better prognosis and easier rehabilitation when developmental abnormalities are identified early on.

The purpose of this study was to compare the results of neurodevelopmental examination at 6 months' corrected age for premature infants that had neonatal seizures and intracranial hemorrhage with theresultsfor neurologicallynomal premature infants.

\section{METHOD}

Sixty-eight premature patients in the Neurodevelopmental Service at Hospital de Clínicas de Porto Alegre (HCPA), Brazil, were selected and divided into two groups: patients who had had intracranial hemorrhage and/or neonatal seizures, and premature infants who had no neurological problems. Patients with cerebral hemorrhage that progressed to hydrocephalus and those with neonatal seizures secondary to infections or genetic causes were excluded from the study.

The groups were compared with respect to sex, race, maternal age, mode of delivery, parity, infant's gestational age, weight for gestational age, birth weight, Apgar score at 5 minutes, use of mechanical ventilation, and sepsis during gestation. Brain ultrasound studies were performed for all patients.
An experienced examiner, blinded to patient's group, examined the neurodevelopmental status of infants at 6 months' corrected age with respect to muscletone, strength, deep tendon reflexes, Moro reflex, head control, sitting with support, and grasping objects. Results were analyzed with the software Epi-Info 6.04; level of significance was $\alpha=$ $0.05, \beta=0.80$, with $95 \%$ confidence intervals.

This study was approved by the Committee for Ethics in Research, HCPA, and conducted after parents signed an informed consent term.

\section{RESULTS}

There were no significant differences between the groups with and without neonatal seizures and/or intracranial hemorrhage with respect to sex, race, parity, gestational age, weight for gestational age, Apgar score, mechanical ventilation, and sepsis during hospitalization (Tables 1 and 2). Six patients had grade I hemorrhage, and five of them had neonatal seizures; three had grade II hemorrhage, and all of them had neonatal seizures; one had grade II hemorrhage and no seizures; two had grade IV hemorrhage, and one of them had neonatal seizures. The factors under study were observed in 17 (25\%) of the 68 patients, and there was a statistically significant correlation between having neonatal seizures and/or hemorrhage $(p=0.000007)$ (Table 3).

There were no differences between patients with intracranial hemorrhage and controls with respect to sex, race, maternal age, mode of delivery, Apgar

Table 1. Pre- and perinatal characteristics.

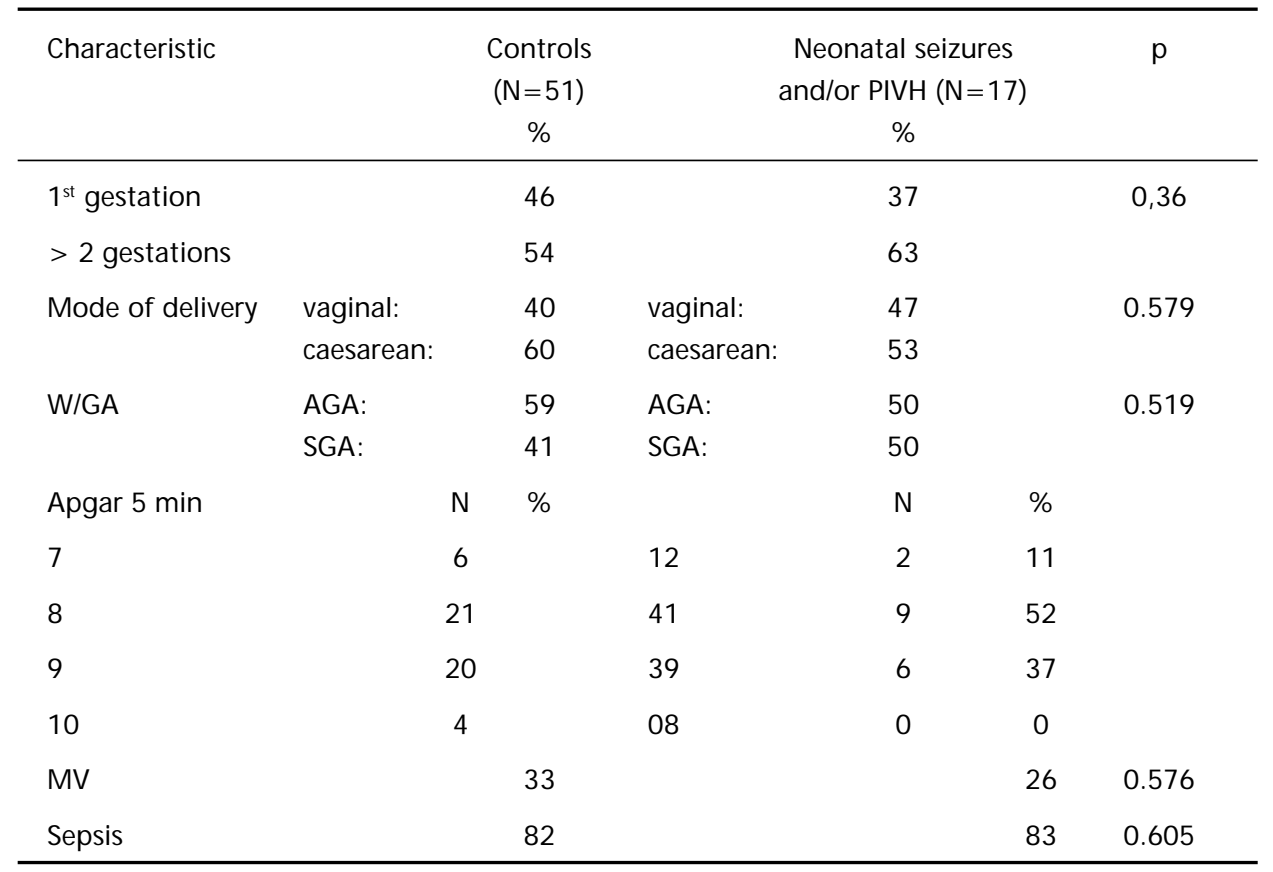

W, weight; GA, gestational age; AGA, adequate for gestational age; SGA, small for gestational age; PIVH, peri- and intraventricular hemorrhage; $M V$, mechanical ventilation. 
Table 2. Mother-infant characteristics.

\begin{tabular}{lccc}
\hline & $\begin{array}{c}\text { Controls }(\mathrm{N}=51) \\
\text { mean }\end{array}$ & $\begin{array}{c}\text { Neonatal seizures and/or PIVH }(\mathrm{N}=17) \\
\text { mean }\end{array}$ & $\mathrm{p}$ \\
\hline Maternal age (years) & 28 & 26 & 0.816 \\
Gestational age (weeks) & 31.6 & 32 & 0.83 \\
Birth weight (grams) & 1254 & 1259 & 0.957 \\
\hline
\end{tabular}

score, gestational age, weight for gestational age, birth weight, mechanical ventilation and sepsis during hospitalization. There was a statistically greater frequency of multiparity in the group of patients with intracranial hemorrhage $(p=0.02)$. The neurodevelopmental examination performed at 6 months' is showed in the Table 4.

There were no differences between patients with seizures and control patients with respect to sex, race, maternal age, mode of delivery, multiparity, Apgar score, gestational age, weight for gestational age, birth weight, mechanical ventilation and sepsis during hospitalization.

Again, no differences were found between patients with intracranial hemorrhage and seizures and control patients with respect to sex, race, maternal age, mode of delivery, multiparity, Apgar score, gestational age, weight for gestational age, birth weight, mechanical ventilation, and sepsis during hospitalization.

\section{DISCUSSION}

Studies about the neurological and psychomotor development of premature infants are quite recent because the mortality rates for these patients used to be very high some years ago ${ }^{7,8}$. The creation and later development of neonatal intensive care units
Table 3. Correlation between neonatal seizures and PIVH.

\begin{tabular}{lcc}
\hline Characteristic & $\mathrm{n}$ & $(\%)$ \\
\hline Neonatal seizures and PIVH & 9 & $(13)$ \\
Neonatal seizures but no PIVH & 5 & $(7)$ \\
PIVH but no seizures & 3 & $(5)$ \\
None & 51 & $(75)$ \\
Total & 68 & $(100)^{*}$ \\
\hline
\end{tabular}

*p, 7X10-6; PIVH, peri- and intraventricular hemorrhage.

promoted a significant decrease in mortality and in the occurrence of bronchopulmonary dysplasia and interstitial emphysema ${ }^{9,10}$. The incidence rate of neurological sequelae in surviving infants is inversely proportional to gestational age $\mathrm{e}^{11}$. Some important physiopathological factor may be associated to the immaturity of the central nervous system (CNS), which results in poor control over the autonomic nervous system (ANS) and, consequently, over spontaneous ventilation in premature infants ${ }^{12}$.

Neonatal seizures are some of the most frequent signs of neurological involvement, and may interfere with vital functions, such as feeding and ventilation $^{13}$. Mortality rates for neonatal seizures have

Table 4. Neurodevelopmental examination and neonatal seizures and/or PIVH.

\begin{tabular}{lccccc}
\hline Characteristic & Controls & $\begin{array}{c}\text { Neonatal seizures } \\
\text { and/or PIVH }\end{array}$ & RR & Cl & p \\
\hline Muscle tone appropriate for CA & $35 / 48$ & $4 / 15$ & 0.37 & $0.16-0.86$ & $0.003^{*}$ \\
Strength appropriate for CA & $41 / 41$ & $7 / 9$ & 0.78 & $0.55-1.1$ & 0.029 \\
Reflexes appropriate for CA & $43 / 44$ & $8 / 13$ & 0.63 & $0.41-0.97$ & $0.001^{*}$ \\
Moro reflex & $2 / 51$ & $3 / 17$ & 4.5 & $0.82-24.7$ & 0.09 \\
Head control & $44 / 44$ & $6 / 8$ & 0.75 & $0.5-1.12$ & $0.021^{*}$ \\
Sitting with support & $45 / 45$ & $12 / 12$ & - & & 1 \\
Grasping 1 object in each hand & $30 / 45$ & $10 / 11$ & 1.36 & $1.03-1.8$ & 0.15 \\
\hline
\end{tabular}

$\mathrm{CA}$, corrected age; PIVH, peri- and intraventricular hemorrhage.*Singnificance 
decreased over the last decades, but there has not been great improvement in relation to sequelae, such as mental retardation and motor deficit. Seizures occur in about $10 \%$ of all patients with intracranial hemorrhage, but this rate is higher for premature infants. Our study revealed a $75 \%$ frequency rate in cases of intracranial hemorrhage, and demonstrated that premature patients are more susceptible to these events. Periventricular and ventricular hemorrhages are associated with prematurity, and their severity is inversely proportional to gestational age ${ }^{14-17}$.

Hypertonia is expected to decrease at 6 months' of age because of the beginning of cortical control over reflex activity. Appendicular hypertonia and hyperreflexia may be strong evidence that cortical control is not efficient yet ${ }^{13}$. At the same age - and following the craniocaudal sequence of neurological development - the infant is expected to hold the head up, sit without support, and grasp objects with both hands. Primitive reflexes of the newborn infant, such as the Moro reflex, should also disappear. Our study analyzed these key elements to measure the damage caused by neonatal seizures and intracranial hemorrhage. About 30 to $60 \%$ of all premature infants with severe intracranial hemorrhage and ventriculomegaly had developmental sequelae, such as cerebral palsy ${ }^{18-19}$. Even when not accompanied by hemorrhage, ventriculomegaly is associated with a higher risk for delay in neurological development ${ }^{20}$. Reports in literature have amply demonstrated that there is a cause and effect relationship between intracranial hemorrhage and seizures in the neonatal period. Therefore, the neurological prognosis may be better when these two events are not associated ${ }^{21}$.

Abnormal results in the neonatal neurological examination are associated with impaired neurological development in premature infants ${ }^{21-23}$. An abnormal result does not always predict developmental problems, but this examination is a good tool to screen this high-risk group of patients who have to be carefully observed and, if necessary, treated. Persistent tone and reflexabnormalities in infancy may suggest cerebral palsy, motor dysfunction, learning or behavioral problems ${ }^{24}$. Our patients' neurodevelopmental examination at 6 months' corrected age revealed inappropriate muscle tone, strength and reflexes, as well as delay in head control, for those patients that had neonatal intracranial hemorrhage and/or seizures. Early neurological assessment is extremely important because its results help making decisions about rehabilitation and prevention of disorders that typically affect these patients.
The association between multiparity and intracranial hemorrhage may be explained by the shorter expulsion stage of babies born to multiparous mothers.

Conclusions - We compared the results of neurodevelopmental examination for two groups of premature infants at 6 months' corrected age. Further studies with these same premature infants are under way, and these patients will be followed up until they reach school age.

\section{REFERENCES}

1. Ehrenkranz RA, Younes N, Lemons JA. Longitudinal growth of hospitalized very low birth weight infants. Pediatrics 1999;104:280-289.

2. Fletcher JM, Landry SH, Bohan TP, et al. Effects of intraventricular hemorrhage and hydrocephalus on the long term neurobehavioral development of preterm very low birthweight infant. Dev Med Child Neurol 1997;39:5966-6016.

3. Rotta NT, Winckler MIB, Ohlweiler $L$, et al. Seguimento neurológico de 90 recém-nascido de alto risco. Revista HCPA 1988;8:162-167.

4. Gherpelli JLD. A valiação neurológica do recém-nascido prematuro. In Diament A, Cypel, S (eds). N eurologia infantil, 3.Ed. A teneu: São PauIo, 1996:22-23.

5. Pedroso FS, Rotta NT. From the foot-mouth reflex to the hand- mouth reflex: a continuum of responses to appendicular compression. Arq Neuropsiquiatr 1997;55:186-192.

6. Riesgo RS, Rotta AT, Rotta NT. Shock of birth. Arq Neuropsiquiartr 1996;54:361-368.

7. Sell EJ. Outcome of very very low birthweight infants. The tiny baby Clin Perinatol 1986;13:451-460.

8. Washington Report: N eonatal intensivecarefor low birthweight infants Costs and effectiveness. Health Technology Case Study 38. Washington, DC: Office of Technology Assessment 1987:7-15.

9. Collaborative European Multicenter Study Group. Surfactant replacement therapy for severeneonatal respiratory distress syndrome: An international randomized clinical trial. Pediatrics 1988;82:683-691.

10. Lang MJ, Hall RT, Reddy NS. A controlled trial of human surfactant replacement therapy for severe respiratory distress syndrome in very low birth weight infants. J Pediatr 1990;116:295-300.

11. Whitfield MF, Johannsen DE. Major disabilities in surviving children of birthweight 800 grams or less in British Columbia: 1974- 1988 births. Pediatr Res 1991;29:1609-1612.

12. Bellig LL. A window on the neonate's brain. Neonatal Network 1989;7:13-20

13. Volpe, JJ. Neonatal Seizures. In Neurology of the Newborn. $3^{\text {th }}$ Philadel phia, W. B. Saunders 1995;172-207.

14. Hill A, Volpe JJ Intracraneal hemorrhage. In A very GB, Fletcher MA Macdonald (EDS). Neonatology-pathofisiology and management of the newborn. 4.Ed. Philadel phia: J.B. Lippincott. 1994:1127-1135.

15. Hack M, Wilson-Costello D, Friedman H, Taylor GH, Schluchter M, Fanaroff AA. Neurodevelopment and predictors of outcomes of children with birth weights of less than 1000g: 1992-1995. Arch Pediatr Adolesc Med 2000;154:725-731.

16. Volpe JJ. Intracranial hemorrhage: germinal matrix-intraventricular haemorrhage of the premature infant. In Neurology of the newborn. $4^{\text {th }}$. Philadel phia, Saunders 2001;428-493.

17. Vohr BR, Wright LL, Dusik AM, et al. Neurodevelopmental and functional outcomes of extremely low birth weight infants the $N$ ational Institute of Child Health and Human Development. Pediatrics 2000;105:1216-1226

18. Papile LA, Munsick-Bruno G, Schaefer A. Relationship of cerebral intraventricular hemorrhageand early chidhood neurologic handicaps. J Pediatr 1983;103:273-277.

19. Shankaran S, KoepkeT, Woldt E, et al. Outcome after posthemorragic ventriculomegaly in comparison with mild hemorrhage without ventriculomegaly. J Pediatr 1989;114:109-114.

20. Stewart AL, Thorburn RJ, Hope PL, et al. Ultrasound appearance of the brain in very preterm infants and neuro-developmental outcome at 18 months of age. Arch Dis Child 1983;58:598-604.

21. Allen MC, CaputeAJ. Neonatal neurodevelopmental examination as a predictor of neuromotor outcome in premature infants. Pediatrics 1989;83:498-506.

22. Brown JK, Purvis RJ, Forfar JO, et al. N eurological aspects of perinatal asphyxia. Dev Med Child Neurol 1974;16:567-580.

23. Ishikawa T, Ogawa Y, Kanayama M, et al. Long-term prognosis of asphyxiated full-term neonates with CNS complications. Brain Dev 1987;9:48-53.

24. Drillien CM, Thomson AJM, BurgoyneK. Low-birthweight children at early school age: a longitudinal study. Dev Med Child Neurol 1980;22:26-47. 